\title{
Two new species of Stenochironomus Kieffer (Diptera, Chironomidae) from Zhejiang, China
}

\author{
Xin Qi', Xiaolong Lin², Yuedan Liu, ${ }^{3,4}$ Xinhua Wang ${ }^{2}$ \\ I College of Life Science, Taizhou University, Taizhou, Zhejiang 318000, China 2 College of Life Science, \\ Nankai University, Tianjin 300071, China 3 The Key Laboratory of Water and Air Pollution Control of \\ Guangdong Province, South China Institute of Environmental Sciences, Ministry of Environment Protection of \\ PRC, Guangzhou 510065, China 4 State Environmental Protection Key Laboratory of Water Environmental \\ Stimulation and Pollution Control, South China Institute of Environmental Sciences, Ministry of Environment \\ Protection of PRC, Guangzhou 510065, China \\ Corresponding author: Xinhua Wang (xhwang@nankai.edu.cn)
}

Academic editor: V. Blagoderov | Received 31 July 2014 | Accepted 6 January 2015 | Published 29 January 2015

http://zoobank.org/B7A22FB0-A7C6-4AF4-A8F0-558B2DF2E58C

Citation: Qi X, Lin X, Liu Y, Wang X (2015) Two new species of Stenochironomus Kieffer (Diptera, Chironomidae) from Zhejiang, China. ZooKeys 479: 109-119. doi: 10.3897/zookeys.479.8364

\begin{abstract}
Two new species of Stenochironomus Kieffer (Diptera: Chironomidae: Chironominae), S. brevissimus sp. n. and S. linanensis sp. n., are described from China and the male imagines are illustrated. S. brevissimus sp. $\mathbf{n}$. can be separated from the so far known species by having very short and small, spatulate superior volsella with two long setae, whereas $S$. linanensis sp. $\mathbf{n}$. is easily separated from the other species of Stenochironomus by the following characters: wings transparent, body yellow, superior volsella finger-like, with nine long setae, elongated inferior volsella with four long setae and one well developed terminal spine; tergite IX with 10-15 long setae medially. A key to the males of Stenochironomus occurring in China is given.
\end{abstract}

\section{Keywords}

Stenochironomus, new species, key, China

\section{Introduction}

Stenochironomus Kieffer, 1919 is a species-rich genus with worldwide distribution, occurring in all biogeographical regions except in Antarctica (Cranston et al. 1989). The genus was erected by Townes in 1945 based on Chironomus pulchripennis (Coquillett, 1902) (Spies and Sæther 2004). The larvae are easily found mining decayed leaves or

Copyright Xin Qi et al. This is an open access article distributed under the terms of the Creative Commons Attribution License (CC BY 4.0), which permits unrestricted use, distribution, and reproduction in any medium, provided the original author and source are credited. 
wood in freshwater habitats ranging from small ponds and swamps to fast-flowing streams and rivers (Cranston et al. 1989). Based on the different hosts of larvae and pupae, Borkent (1984) erected two subgenera: Stenochironomus s. str. Kieffer (larvae and pupae mine dead submerged wood) and Petalopholeus Borkent (larvae and pupae mine dead submerged leaves). This subdivision has not been adopted by subsequent authors, because immature stages are known only for a few species, which makes difficult to ascribe them to any subgenus (Pinho et al. 2005, Andersen et al. 2008, Qi et al. 2008, Dantas et al. 2010, Zorina 2010). To date, there are 97 species recorded around the word: 24 species from the Palaearctic Region, 17 from the Nearctic Region, 30 from the Neotropical Region, 16 from the Oriental Region, 16 from the Afrotropical Region and 4 from the Australasian Region (Qi et al. 2011, Reis et al. 2013).

Zhejiang Province is located in the Chinese central subtropical region, which has a humid monsoon climate. In Zhejiang, three species of Stenochironomus [S. koreanus Borkent, 1984, S. nubilipennis Yamamoto, 1981 and S. satorui (Tokunaga \& Kuroda, 1936)] have been recorded (Wang 2000, Qi et al. 2011). In this paper, two new species of Stenochironomus from Zhejiang, Oriental China, are described and illustrated. A key to the males of Stenochironomus from China is presented.

\section{Materials and methods}

The morphological nomenclature follows Sxther (1980). Measurement methods follow Qi et al. (2012). The material examined was slide-mounted, following the procedure outlined by Sæther (1969). Specimens have been deposited in the College of Life Science, Taizhou University, China.

Abbreviations of parts measured are as follows:

AR Antennal ration, length of $13^{\text {th }} /$ length of flagellomeres 1-12

Palpomere ratio (5th/3rd) Length of the $5^{\text {th }}$ Palpomere / length of the $3^{\text {rd }}$ Palpomere

VR Venarum ration, length of Cubitus $(\mathrm{Cu}) /$ length of Media (M)

BV Length of (femur + tibia $\left.+\mathrm{ta}_{1}\right) /$ length of $\left(\mathrm{ta}_{2}+\mathrm{ta}_{3}+\mathrm{ta}_{4}+\mathrm{ta}_{5}\right)$

LR Leg ration, length of $\mathrm{ta}_{1} /$ length of tibia

SV Length of (femur + tibia) / length of $\mathrm{ta}_{1}$

HR Hypopygium ration, length of gonocoxite / length of gonostylus

HV Hypopygium value, total length / length of gonostylus times ten

$\mathbf{p}_{1} \quad$ Fore leg

$\mathbf{p}_{2} \quad$ Mid leg

$\mathbf{p}_{3} \quad$ Hind leg

fe femur

ti tibia

ta $_{1} \ldots$ ta $_{\mathbf{n}}$ tarsus $_{1} \ldots$ tarsus $_{n}$

$\mathbf{R}$ Radius

$\mathbf{R}_{1} \quad$ Radius 1 vein

$\mathbf{R}_{4+5}$ Radius $4+5$ vein 


\section{Taxonomy}

Stenochironomus brevissimus sp. $\mathrm{n}$.

http://zoobank.org/ADC155AF-0069-4052-8907-191E35A59854

Figs $1-10$

Diagnosis. The adult male of $S$. brevissimus sp. n. can be distinguished from all other species of Stenochironomus by the following combination of characters: superior volsella very short and small, spatulate, with 2 long setae, elongated inferior volsella with 6 long setae, posterior margin of tergite IX with 20-22 setae and 8 spines.

Description. Male imago $(\mathrm{n}=3)$. Total length $4.3-4.6 \mathrm{~mm}$. Wing length $2.2-2.5$ $\mathrm{mm}$. Total length / wing length 1.8-1.9. Wing length / length of profemur 1.7-1.8.

Coloration. Head yellow, antenna brown. Thorax light yellow, postnotum and scutum with brown spots. Wings transparent, without any pigmentation. Abdomen and hypopygium yellow, anal point brown. Fore legs yellow with femur apically brown. Mid legs with apex and posterior basal region of femur with dark brown stripes, tibia brown, tarsomeres $1-5$ yellow. Hind legs brown with femur yellow with dark brown stripes at apex.

Head (Fig. 1). AR 1.80-1.92. Temporal with 10-12 setae. Clypeus with 20-22 setae. Tentorium 173-176 mm long, 43-46 mm wide. Stipes 140-145 $\mu \mathrm{m}$ long, 10-13 $\mu \mathrm{m}$ wide. Palpomere lengths (in mm): 60-63, 60-65, 210-230, 140-150, 260-300. Palpomere ratio $\left(5^{\text {th }} / 3^{\text {rd }}\right) 1.2-1.3$.

Wings (Fig. 2). VR 1.08-1.15. Brachiolum with 3-4 setae; $\mathrm{R}$ with $25-32$ setae, $\mathrm{R}_{1}$ with 27-30 setae, $\mathrm{R}_{4+5}$ with 41-42 setae. Squama with 8-10 setae.

Thorax (Fig. 3). Dorsocentrals 12-14, acrostichals 14-16, prealars 4-5. Scutellum with 6-7 setae.

Legs (Fig. 4). Fore leg: width at apex of tibia $60-65 \mathrm{~mm}$, tibia with scale 53-56 $\mu \mathrm{m}$ long, with 2-4 strong setae (Fig. 5). Mid leg: width at apex of tibia $80-83 \mathrm{~mm}$, tibia with two apical spurs 40-50, 43-53 $\mu \mathrm{m}$ long. Hind leg: width at apex of tibia $70-80 \mathrm{~mm}$, tibia with two apical spurs $40-50,40-55 \mu \mathrm{m}$ long. Mid and hind tibiae with fused combs (Figs 6-7), each comb 36-50 $\mu \mathrm{m}$ long. Lengths (in $\mathrm{mm}$ ) and proportions of legs in Table 1.

Hypopygium (Fig. 8). Anal point 113-120 mm long, 15-20 $\mu \mathrm{m}$ wide at base, 13-15 $\mu \mathrm{m}$ wide at apex, parallel-sided, slender, apically rounded. Tergite IX with 16-17 long setae medially, posterior margin of tergite IX with 20-22 setae and 8 spines (Fig. 9). Phallapodeme 120-123 mm long; transverse sternapodeme 30-50 $\mathrm{mm}$ long. Gonocoxite 200-230 mm long. Superior volsella short, small and spatulate, 16-18 mm long, 20-22 mm wide, with 2 long setae (Fig. 10). Inferior volsella elongated, 190-200 mm long, with 6 long setae. Gonostylus 210-230 mm long, with 4 long setae along inner margin in distal 1/3. HR 0.95-1.00, HV 1.89-2.04.

Female, pupa and larva. Unknown.

Type material. Holotype: Male, CHINA, Zhejiang, Quzhou City, Hunan County, 19.iv.2012, leg. XL Lin, sweep net. 2 Paratypes: 2 males, same data as holotype. 
Table I. Lengths (in $\mu \mathrm{m})$ and proportions of leg segments in Stenochironomus brevissimus sp. $\mathrm{n} .(\mathrm{n}=3)$.

\begin{tabular}{c|c|c|c}
\hline & $\mathbf{p}_{\mathbf{1}}$ & $\mathbf{p}_{\mathbf{2}}$ & $\mathbf{p}_{3}$ \\
\hline $\mathrm{Fe}$ & $1300-1400$ & $1125-1200$ & $1325-1525$ \\
\hline $\mathrm{Ti}$ & $1300-1500$ & $1000-1125$ & $1275-1400$ \\
\hline $\mathrm{ta}_{1}$ & $1500-1600$ & $725-800$ & $950-1100$ \\
\hline $\mathrm{ta}_{2}$ & $775-875$ & $375-450$ & $525-625$ \\
\hline $\mathrm{ta}_{3}$ & $675-750$ & $340-410$ & $440-500$ \\
\hline $\mathrm{ta}_{4}$ & $525-600$ & $200-290$ & $260-360$ \\
\hline $\mathrm{ta}_{5}$ & $250-300$ & $90-110$ & $110-130$ \\
\hline $\mathrm{LR}$ & $1.07-1.15$ & $0.71-0.73$ & $0.74-0.79$ \\
\hline $\mathrm{BV}$ & $1.78-1.84$ & $2.48-2.83$ & $2.49-2.66$ \\
\hline $\mathrm{SV}$ & $1.73-1.81$ & $2.91-2.95$ & $2.66-2.74$ \\
\hline
\end{tabular}

Table 2. Main differences between S. brevissimus sp. n., S. hainanus and S. okialbus.

\begin{tabular}{|c|c|c|c|}
\hline & S. brevissimus & S. hainanus & S. okialbus \\
\hline Wing & $\begin{array}{l}\text { transparent, without any } \\
\text { pigmentation }\end{array}$ & $\begin{array}{l}\text { transparent, without } \\
\text { any pigmentation }\end{array}$ & $\begin{array}{l}\text { with dark bands across the } \\
\text { middle and posterior area }\end{array}$ \\
\hline Coloration & $\begin{array}{l}\text { thorax light yellow, } \\
\text { postnotum and scutum } \\
\text { with brown spots; fore legs } \\
\text { yellow with femur apically } \\
\text { brown; mid legs with } \\
\text { apex and posterior basal } \\
\text { region of femur with dark } \\
\text { brown stripes, tibia brown, } \\
\text { tarsomeres } 1-5 \text { yellow; } \\
\text { hind legs brown with femur } \\
\text { yellow with dark brown } \\
\text { stripes at apex }\end{array}$ & $\begin{array}{c}\text { whole body yellow, } \\
\text { without dark } \\
\text { pigmentation }\end{array}$ & $\begin{array}{l}\text { thorax yellow; fore legs yellow } \\
\text { with femur apically brown, } \\
\text { apex and basal region of tibia } \\
\text { with dark brown stripes; mid } \\
\text { legs yellow with femur apically } \\
\text { brown; hind legs yellow with } \\
\text { femur apically brown }\end{array}$ \\
\hline Superior volsella & with 2 setae & with 3 setae & with 4 setae \\
\hline Inferior volsella & with 6 setae & with 3 setae & $\begin{array}{l}\text { with } 4 \text { setae and a strong } \\
\text { terminal spine }\end{array}$ \\
\hline $\begin{array}{l}\text { Posterior margin } \\
\text { of tergite IX }\end{array}$ & with $20-22$ setae and 8 spines & with 16 setae & with 8 setae and 8 spines \\
\hline
\end{tabular}

Etymology. The specific epithet is a Latin adjective "brevissimus", meaning the shortest, and refers to the superior volsella, which is the shortest in the genus.

Remarks. S. brevissimus sp. n. is similar to S. hainanus Qi, Shi \& Wang, 2008 and S. okialbus Sasa, 1990 in having short and small superior volsella, but can separated from these species by the differences given in Table 2 .

Distribution. The species is currently known only from Zhejiang Province of Oriental China. 

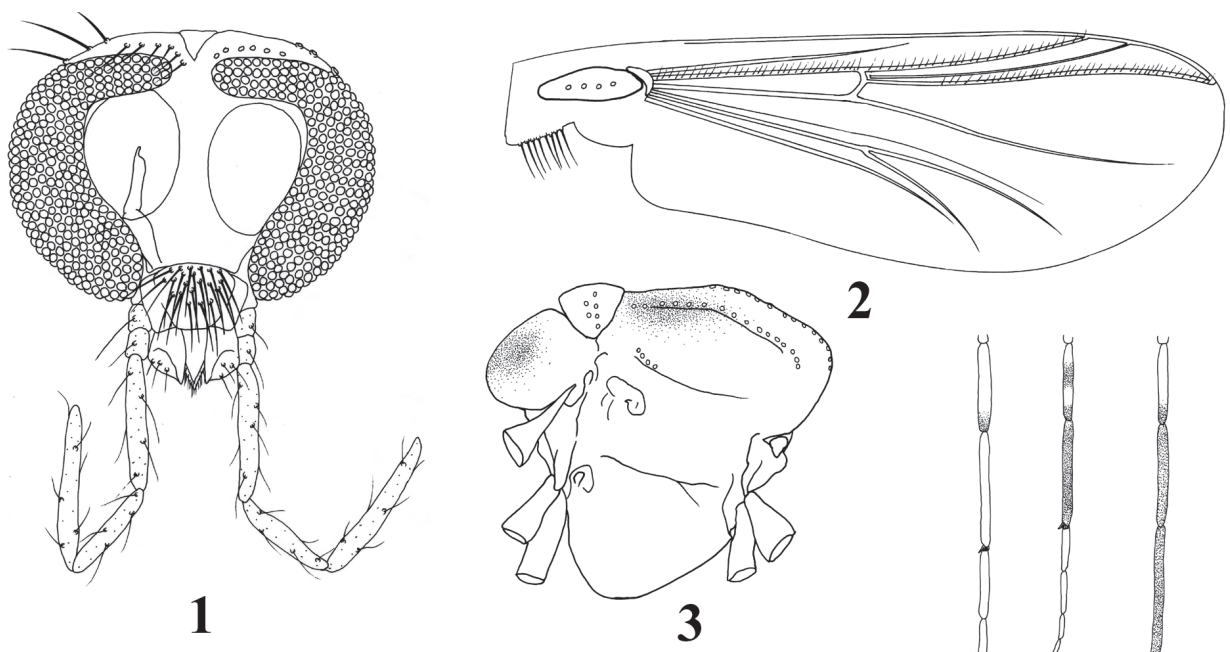

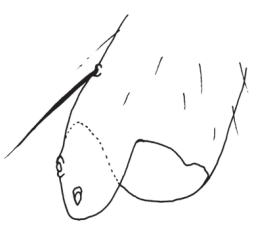

5

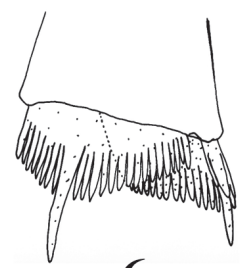

6

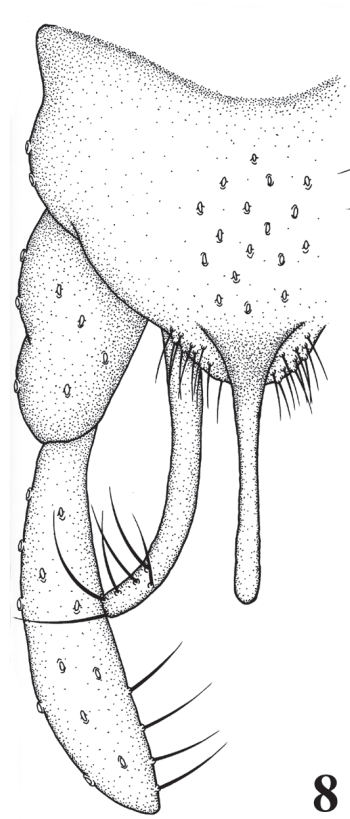

8

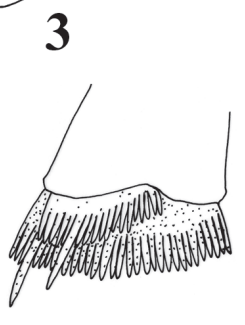

7
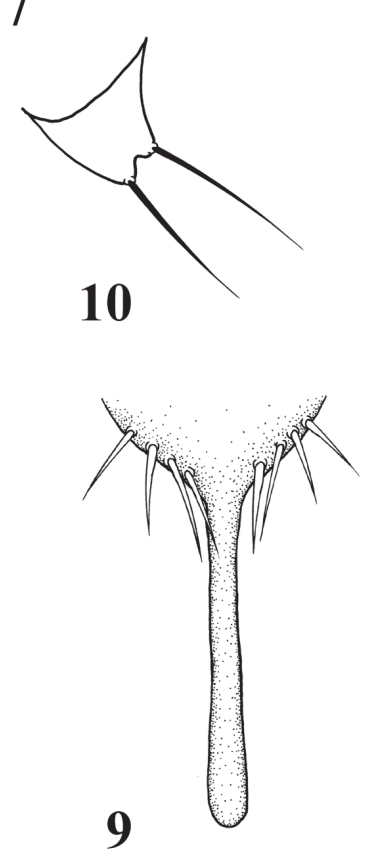

Figures I-10. Stenochironomus brevissimus sp. n., male. I head $\mathbf{2}$ wing $\mathbf{3}$ thorax, lateral view $\mathbf{4}$ legs coloration (a. fore leg; b. mid leg; c. hind leg) $\mathbf{5}$ fore tibial apex, ventral view $\mathbf{6}$ mid tibial apex, lateral view $\mathbf{7}$ hind tibial apex, lateral view 8 hypopygium 9 spines on posterior margin of tergite IX, ventral view 10 superior volsella. 


\section{Stenochironomus linanensis sp. $\mathbf{n}$.}

http://zoobank.org/F01888A4-0CA1-4041-9290-12B68CFA5BA0

Figs $11-18$

Diagnosis. The adult male of $S$. linanensis sp. n. can be distinguished from all other species of Stenochironomus by the following combination of characters: wings transparent, body yellow, superior volsella finger-like, with 9 long setae, elongated inferior volsella with 4 long setae and one well-developed terminal spine, tergite IX with 10-15 long setae medially.

Description. Male imago $(\mathrm{n}=5)$. Total length $2.9-3.8 \mathrm{~mm}$. Wing length $1.4-1.5 \mathrm{~mm}$. Total length / wing length 1.98-2.41. Wing length / length of profemur 1.30-1.57.

Coloration. Head yellow. Thorax greenish yellow. Wings transparent, without any pigmentation. Abdomen yellow, hypopygium brown. Legs pale yellow.

Head (Fig. 11). AR 1.20-1.32. Temporal with 8-14 setae. Clypeus with 9-10 setae. Tentorium 153-156 mm long, 37-42 mm wide. Stipes 72-95 $\mu \mathrm{m}$ long, 5-6 $\mu \mathrm{m}$ wide. Palpomere lengths (in $\mathrm{mm}$ ): 45-47, 28-33, 53-60, 75-90, 110-120. Palpomere ratio $\left(5^{\text {th }} / 3^{\text {rd }}\right) 2.00-2.07$.

Wings (Fig. 12). VR 1.07-1.20. Brachiolum with 2 setae; $\mathrm{R}$ with 16-23 setae, $\mathrm{R}_{1}$ with 17-18 setae, $\mathrm{R}_{4+5}$ with $22-28$ setae. Squama with 5-7 setae.

Thorax (Fig. 13). Dorsocentrals 9-13, acrostichals 9-14, prealars 4-5. Scutellum with 5-6 setae.

Legs. Fore leg: width at apex of tibia $33-47 \mathrm{~mm}$, tibia with scale $33-46 \mu \mathrm{m}$ long, with 2-3 strong setae (Fig. 14). Mid leg: width at apex of tibia 50-65 mm, tibia with two apical spurs 25-28, 30-40 $\mu \mathrm{m}$ long. Hind leg: width at apex of tibia 50-60 mm, tibia with two apical spurs 32-39, 35-40 $\mu \mathrm{m}$ long. Mid and hind tibiae with fused combs (Fig. 15-16), each comb 18-22 $\mathrm{mm}$ long. Lengths (in $\mathrm{mm}$ ) and proportions of legs in Table 3.

Hypopygium (Fig. 17). Anal point $65-73 \mathrm{~mm}$ long, 14-20 $\mu \mathrm{m}$ wide at base, 6-8 $\mu \mathrm{m}$ wide at apex, apex of anal point slightly swollen and rounded. Tergite IX

Table 3. Lengths (in $\mu \mathrm{m}$ ) and proportions of leg segments in Stenochironomus linanensis sp. $\mathrm{n}$.

\begin{tabular}{c|c|c|c}
\hline & $\mathbf{p}_{\mathbf{1}}$ & $\mathbf{p}_{\mathbf{2}}$ & $\mathbf{p}_{\mathbf{3}}$ \\
\hline $\mathrm{fe}$ & $925-1075$ & $625-700$ & $650-725$ \\
\hline $\mathrm{ti}$ & $700-875$ & $650-725$ & $750-900$ \\
\hline $\mathrm{ta}_{1}$ & $925-1100$ & $475-550$ & $780-950$ \\
\hline $\mathrm{ta}_{2}$ & $500-725$ & $200-260$ & $400-600$ \\
\hline $\mathrm{ta}_{3}$ & $400-500$ & $210-300$ & $300-350$ \\
\hline $\mathrm{ta}_{4}$ & $320-400$ & $130-200$ & $240-300$ \\
\hline $\mathrm{ta}_{5}$ & $140-200$ & $70-80$ & $100-120$ \\
\hline $\mathrm{LR}$ & $1.25-1.32$ & $0.73-0.75$ & $1.04-1.06$ \\
\hline $\mathrm{BV}$ & $1.67-1.88$ & $2.35-2.87$ & $1.88-2.10$ \\
\hline $\mathrm{SV}$ & $1.76-1.83$ & $2.60-2.68$ & $1.71-1.79$ \\
\hline
\end{tabular}



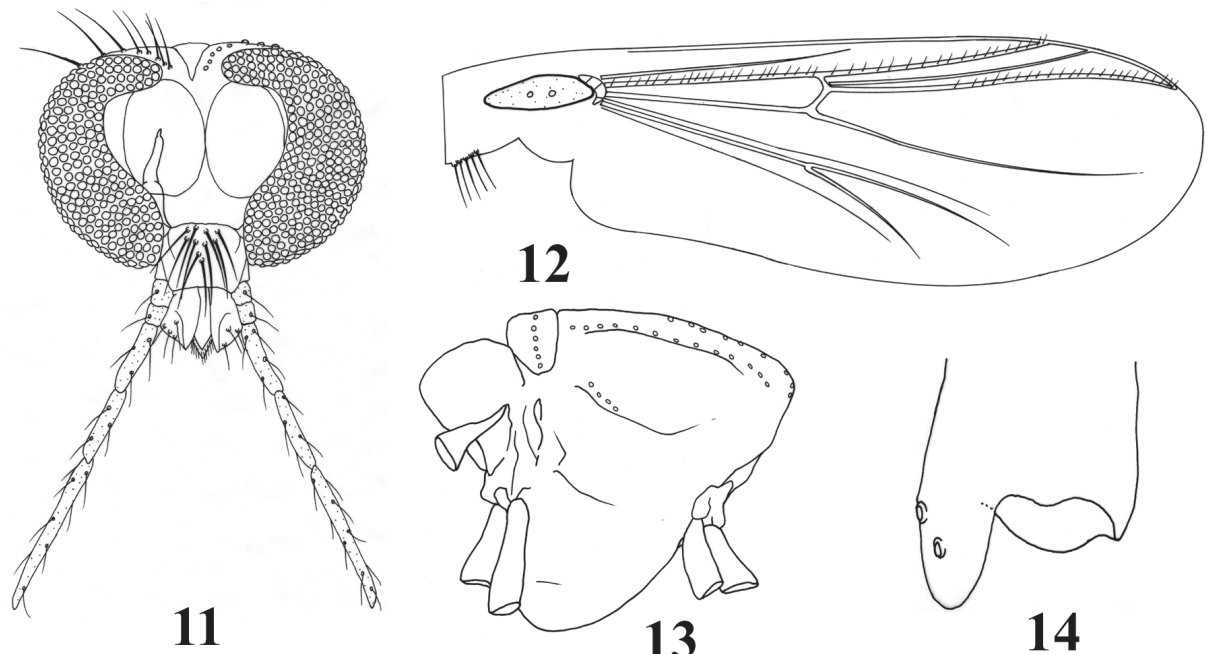

13

14
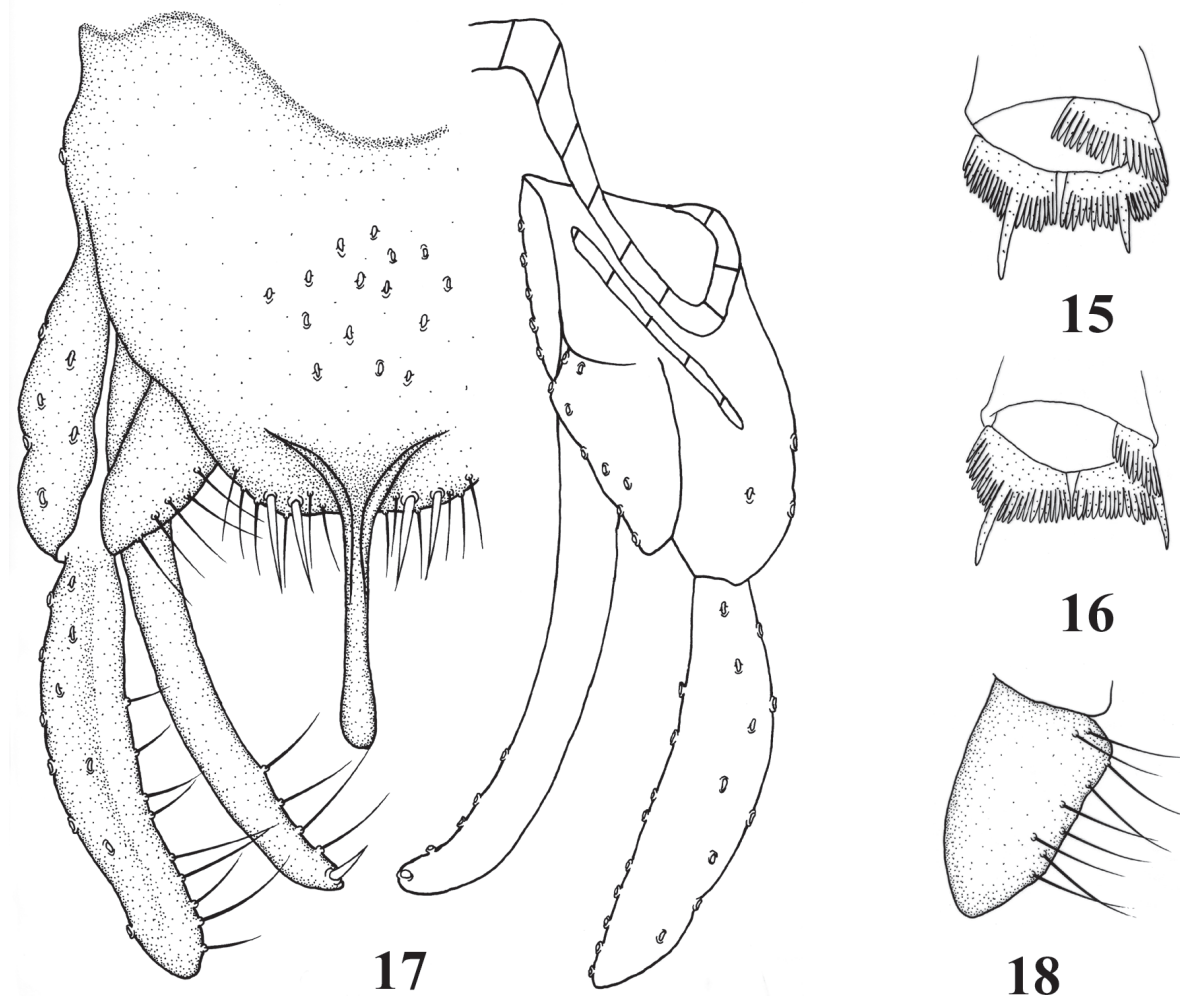

15

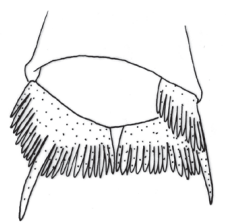

16

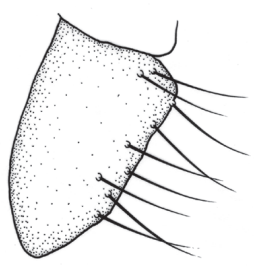

18

Figures I I-I 8. Stenochironomus linanensis sp. n., male. I I head $\mathbf{I} \mathbf{2}$ wing $\mathbf{I} \mathbf{3}$ thorax, lateral view $\mathbf{I} \mathbf{4}$ fore tibial apex, ventral view $\mathbf{I} \mathbf{5}$ mid tibial apex, lateral view $\mathbf{1 6}$ hind tibial apex, lateral view $\mathbf{1 7}$ hypopygium 18 superior volsella. 
Table 4. Main differences between S. linanese sp. n., S. macateei, S. maculatus and S. recticaudatus.

\begin{tabular}{|c|c|c|c|c|}
\hline & S. linanese & S. macateei & S. maculatus & S. recticaudatus \\
\hline Wing & transparent & transparent & $\begin{array}{l}\text { entire wing with } \\
\text { pigmentation }\end{array}$ & transparent \\
\hline $\begin{array}{l}\text { Median setae of } \\
\text { tergite IX }\end{array}$ & $10-15$ & $35-37$ & $25-28$ & $35-37$ \\
\hline $\begin{array}{l}\text { posterior margin } \\
\text { of tergite IX }\end{array}$ & $\begin{array}{c}\text { with } 12-14 \text { setae } \\
\text { and } 4 \text { spines }\end{array}$ & $\begin{array}{l}\text { with } 8 \text { setae } \\
\text { and } 6 \text { spines }\end{array}$ & $\begin{array}{c}\text { with } 8 \text { setae and } 4 \\
\text { spines }\end{array}$ & $\begin{array}{c}\text { with } 14 \text { setae and } 8 \\
\text { spines }\end{array}$ \\
\hline Anal point & $\begin{array}{l}\text { apex of anal point } \\
\text { slightly swollen } \\
\text { and rounded }\end{array}$ & parallel-sided & $\begin{array}{l}\text { apex of anal point } \\
\text { slightly swollen and } \\
\text { rounded }\end{array}$ & $\begin{array}{l}\text { apex of anal point } \\
\text { slightly swollen and } \\
\text { rounded }\end{array}$ \\
\hline Superior volsella & with 9 setae & with $4-5$ setae & with 4-6 setae & with 6 setae \\
\hline Coloration & $\begin{array}{c}\text { whole body } \\
\text { yellow, without } \\
\text { dark pigmentation }\end{array}$ & $\begin{array}{c}\text { whole body } \\
\text { yellow, } \\
\text { without dark } \\
\text { pigmentation }\end{array}$ & $\begin{array}{l}\text { postnotum, scutum } \\
\text { and scutellum with } \\
\text { dark pigmentation; } \\
\text { other parts of body } \\
\text { yellow }\end{array}$ & $\begin{array}{c}\text { dark pigmentation } \\
\text { entirely absent except } \\
\text { on tarsomeres 3-5 of } \\
\text { all legs }\end{array}$ \\
\hline
\end{tabular}

with 10-15 long setae medially, posterior margin of tergite IX with $12-14$ setae and 4 spines. Phallapodeme 70-80 mm long; transverse sternapodeme $35-38 \mathrm{~mm}$ long. Gonocoxite 160-180 mm long. Superior volsella finger-like, 53-63 mm long, 25-27 $\mathrm{mm}$ wide, with 9 long setae (Fig. 18). Inferior volsella elongated, 160-170 mm long, with 4 long setae and one well-developed terminal spine. Gonostylus $123-170 \mathrm{~mm}$ long, with 9 long setae along inner margin in distal 1/2. HR 0.94-1.47, HV 1.98-2.35.

Female, pupa and larva. Unknown.

Type material. Holotype: Male, CHINA, Zhejiang, Linan City, Qingliangfeng Mountain, 16.v.2012, leg. XL Lin, sweep net. 4 Paratypes: 4 males, same data as holotype.

Etymology. The specific epithet is an adjective referring to the type locality, Linan City.

Remarks. S. linanensis sp. n. is similar to $S$. macateei (Malloch, 1905), S. maculatus Borkent, 1984 and S. recticaudatus Borkent, 1984 in the structure of the hypopygium and the inferior volsella with a strong terminal spine, but can be separated from these species by the differences given in Table 4 .

Distribution. The species is known from Zhejiang Province of Oriental China.

\section{Key to males of the genus Stenochironomus in China}

1 Inferior volsella with a well-developed terminal spine ................................ 2

- Inferior volsella without a well-developed terminal spine .............................

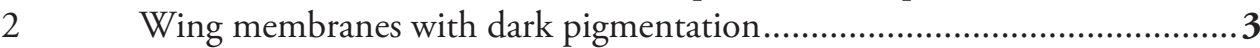

- Wing membranes without any pigmentation............................................ 4

3 Legs almost entire brown, posterior area smoky area between veins $\mathrm{C}$ and $\mathrm{M}$ pale 
- $\quad$ Legs yellow; entire wing smoky gray S. maculatus Borkent, 1984 Superior volsella with 9 setae; posterior margin of tergite IX with 12-14 setae and 4 spines S. linanensis sp. $\mathrm{n}$. Superior volsella with 4 setae; posterior margin of tergite IX with 14-16 setae.

S. koreanus Borkent, 1984 Posterior edge of tergite IX with 8 long setae and 6 spines; anal point parallelsided

S. macateei (Malloch, 1915)

- $\quad$ Posterior edge of tergite IX with 14 long setae, without any spine; anal point roughly triangular, apically pointed...S. mucronatus $\mathrm{Qi}$, Shi \& Wang, 2008 Wing membranes with dark pigmentation

Wings without any pigmentation or with narrow pigment areas around RM and along veins $\mathrm{M}_{3+4}$ and $\mathrm{Cu}_{1}$ Abdominal tergites I-IV light yellow, tergites V-VIII light brown, hypopygium dark brown.

Preepisternum with brown spots; anal point slender and parallel-sided, apically rounded S. nubilipennis Yamamoto, 1981

- $\quad$ Preepisternum without any pigmentation; anal point slender and parallelsided, apically pointed S. satorui (Tokunaga \& Kuroda, 1936)

10 Posterior margin of tergite IX with spines S. brevissimus sp. $\mathbf{n}$. Posterior margin of tergite IX without spines

Entire body yellow, without dark pigmentation; wings transparent, without any pigmentation; inferior volsella with 3 long setae

S. hainanus Qi, Shi \& Wang, 2008

- $\quad$ Body yellow, with brown spots on thorax, abdomen, hypopygium and legs; wings with narrow pigment areas around $\mathrm{RM}$ and along veins $\mathrm{M}_{3+4}$ and $\mathrm{Cu}_{1}$; inferior volsella with 6 long setae

S. totifuscus Sublette, 1960

\section{Acknowledgements}

Financial support from the National Natural Science Foundation of China (NSFC, grant No. 31301908, 31272284) and the Zhejiang Provincial Natural Science Foundation of China (grant No. Y3100486) are acknowledged with thanks.

\section{References}

Andersen T, Mendes HF, Pinho LC (2008) Two new species of Stenochironomus Kieffer from the Brazilian Atlantic Rainforest (Diptera: Chironomidae). Studia Dipterologica 14(2): 263-269. 
Borkent A (1984) The systematics and phylogeny of the Stenochironomus complex (Xestochironomus, Harrisius, and Stenochironomus) (Diptera: Chironomidae). Memoirs of the Entomological Society of Canada 128: 1-269. doi: 10.4039/entm116128fv

Coquillett DW (1902) New Diptera from North America. Kessinger Publishing, Montana, 50 pp. Cranston PS, Dillon ME, Pinder CV, Reiss F (1989) The adult males of Chironominae (Diptera: Chironomidae) of the Holarctic region - Keys and diagnoses. In: Wiederholm T (Ed.) Chironomidae of the Holarctic region. Keys and diagnoses: Part 3. Adult males. Entomologica Scandinavica Supplement 34: 353-532.

Dantas GPS, Hamada N, Mendes HF (2010) A new Neotropical species of the genus Stenochironomus Kieffer (Diptera: Chironomidae) with wood-mining larvae. Zootaxa 2490: 47-54.

Fabricius JC (1805) Systema antliatorum secundum ordines, genera, species adiectis synonymis, locis, observationibus, descriptionibus. K. Reichard, Brunswick, 373 pp.

Kieffer JJ (1919) Chironomiden der Nordlichen Polarregion. Entomologische Mitteilungen 8: $40-48$.

Malloch JR (1915) Four new North American Diptera. Proceedings of the Biological Society of Washington 28: 45-48.

Pinho LC, Mendes HF, Marcondes CB (2005) A new Brazilian species of Stenochironomus Kieffer mining decayed leaves in bromeliads (Diptera: Chironomidae). Zootaxa 1046: 37-47.

Qi X, Shi SD, Wang XH (2008) Two new species and new record of the genus Stenochironomus (Diptera, Chironomidae). Acta Zootaxonomica Sinica 33(3): 526-531.

Qi X, Shi SD, Lin XL, Wang XH (2011) The genus Stenochironomus Kieffer (Diptera: Chironomidae) with three newly recorded species from China. Entomotaxonomia 33(3): 220-330.

Qi X, Lin XL, Wang XH (2012) Review of Dicrotendipes Kieffer from China (Diptera: Chironomidae). ZooKeys 183: 23-36. doi: 10.3897/zookeys.183.2834

Reis EDA, Filho AS, Ferreira-Keppler RL (2013) Two new species and records of Stenochironomus Kieffer from Brazilian Amazon region, with description of immature stages (Diptera: Chironomidae). Zootaxa 3710(5): 449-466. doi: 10.11646/zootaxa.3710.5.4

Sasa M (1990) Studies on the chironomid midges (Diptera, Chironomidae) of the Nansei Islands, southern Japan. Journal of Experimental Medicine 60: 111-165.

Sasa M, Suzuki H (2001) Studies on the chironomid species collected in Hokkaido in September, 2000. Tropical Medicine 43: 1-38.

Sæther OA (1969) Some Nearctic Podonominae, Diamesinae and Orthocladiinae (Diptera: Chironomidae). Bulletin of the Fisheries Research Board of Canada 170: 1-154.

Sæther OA (1980) Glossary of chironomid morphology terminology (Diptera: Chironomidae). Entomologica Scandinavica Supplement 14: 1-51.

Sublette JE (1960) Chironomid midges of California. I, Chironominae, exclusive of Tanytarsini (=Calopsectrini). Proceedings of the United States National Museum 112: 197-226. doi: 10.5479/si.00963801.112-3435.197

Spies M, Sæther OA (2004) Notes and recommendations on taxonomy and nomenclature of Chironomidae (Diptera). Zootaxa 752: 1-90.

Tokunaga M, Kuroda M (1936) Stenochironomid midge from Japan (Diptera), with notes on controlling methods of a leaf mining midge. The Transactions of the Kansai Entomological Society 7: 1-6. 
Townes HK (1945) The Nearctic species of Tendipedini. (Diptera: Tendipedidae (= Chironomidae)). American Midland Naturalist 34: 1-206. doi: 10.2307/2421112

Wang XH (2000) A revised checklist of Chironomidae from China (Diptera). In: Hoffrichter O (Ed.) Late 20th Century Research on Chironomidae. An Anthology from the 13th International Symposium on Chironomidae. Shaker Verlag, Achen, 629-652.

Yamamoto M (1981) Two new species of the genus Stenochironomus from Japan (Diptera: Chironomidae). Bulletim Kitakyushu Museum of Natural History 3: 41-51.

Zorina OV (2010) A new species of Stenochironomus Kieffer (Diptera, Chironomidae) from the Russian Far East. Euroasian Entomological Journal 9 (3): 371-374. 